This item was submitted to Loughborough's Research Repository by the author.

Items in Figshare are protected by copyright, with all rights reserved, unless otherwise indicated.

\title{
Complex low volume electronics simulation tool to improve yield and reliability
}

PLEASE CITE THE PUBLISHED VERSION

\section{PUBLISHER}

(C) IEEE

\section{VERSION}

VoR (Version of Record)

\section{LICENCE}

CC BY-NC-ND 4.0

\section{REPOSITORY RECORD}

Segura-Velandia, Diana M., Paul P. Conway, Andrew A. West, David C. Whalley, Antony R. Wilson, and Lina A.M. Huertas-Quintero. 2019. "Complex Low Volume Electronics Simulation Tool to Improve Yield and Reliability". figshare. https://hdl.handle.net/2134/4216. 
This item was submitted to Loughborough's Institutional Repository (https://dspace.lboro.ac.uk/) by the author and is made available under the following Creative Commons Licence conditions.

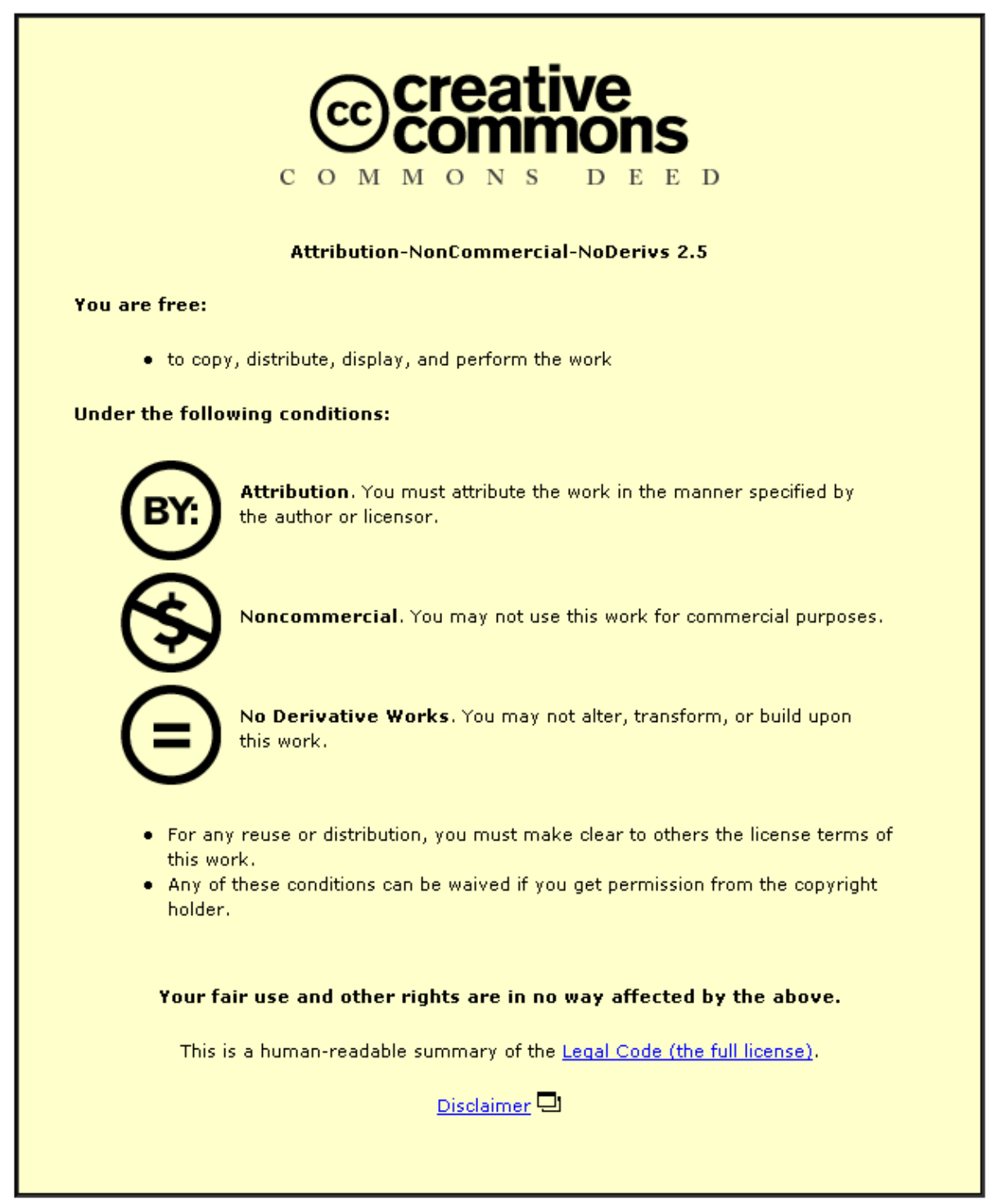

For the full text of this licence, please go to: http://creativecommons.org/licenses/by-nc-nd/2.5/ 


\title{
Complex Low Volume Electronics Simulation Tool to Improve Yield and Reliability
}

\author{
Diana M. Segura Velandia, Paul P. Conway, Andrew A. West, David Whalley, Antony Wilson, Lina Huertas \\ Wolfson School of Mechanical and Manufacturing Engineering \\ Loughborough University, Leics, LE11 3TU, United Kingdom \\ Tel. +440519227677
}

\begin{abstract}
Assembly of Printed Circuit Boards (PCB) in low volumes and a high-mix requires a level of manual intervention during product manufacture, which leads to poor first time yield and increased production costs. Failures at the component-level and failures that stem from non-component causes (i.e. system-level), such as defects in design and manufacturing, can account for this poor yield. These factors have not been incorporated in prediction models due to the fact that systemfailure causes are not driven by well-characterised deterministic processes. A simulation and analysis support tool being developed that is based on a suite of interacting modular components with well defined functionalities and interfaces is presented in this paper. The CLOVES (Complex Low Volume Electronics Simulation) tool enables the characterisation and dynamic simulation of complete design; manufacturing and business processes (throughout the entire product life cycle) in terms of their propensity to create defects that could cause product failure. Details of this system and how it is being developed to fulfill changing business needs is presented in this paper. Using historical data and knowledge of previous printed circuit assemblies (PCA) design specifications and manufacturing experiences, defect and yield results can be effectively stored and re-applied for future problem solving. For example, past PCA design specifications can be used at design stage to amend designs or define process options to optimise the product yield and service reliability.
\end{abstract}

\section{Introduction}

The manufacturing of safety critical electronics is increasingly posed with serious challenges, due to (i) rapid changes in the supply chain e.g. the electronic components' industry since the mid-1990s has accelerated component obsolescence and decreased sources of manufacturing of electronic components [1] and, (ii) environmental regulations restricting the use of certain materials in electronics products [2]. Companies are also making use of commercial-off-theshelf (COTS) components [3] which have short design and production lives that make it difficult to support existing designs, hence forcing expensive re-designs or purchasing stocks of components as they reach end of production life [4]. These challenges impose a tougher competitive situation that has led to increasing attention being paid to customer satisfaction, of which timely and customised services are the key concepts. In reply to these pressures, there has been a shift in the business model developed, through outsourcing many of the activities. However, the tools available to the industry to meet customer requirements and demands while dealing with a dynamic and unreliable supply chain have several challenges [5].
This condition is resulting in global industry concerns with respects to: (i) product reliability, (ii) product quality and (iii) customer satisfaction. Tools that can support the new business model (i.e. dynamic links in all areas of the enterprise) throughout the whole product's life cycle are required. In the past decade, research has focused on dealing with minimising each of these effects by developing design for all desirable processes (DfX) tools that cover various aspects of the product (i.e. PCA) life cycle. The literature covering these topics is vast. Hence, the outline presented as follows gives only a partial view of the discipline. In addition, industry is adapting rapidly to the market conditions and the development of "in-house" systems are generally not documented or discussed thoroughly in the public domain. Consequently, many significant developments including some of those mentioned here are not discussed in detail in this paper. The applications described are limited to those developed by academic organisations aiming at early detection and assessment of assembly problems and representation of the information management schema necessary to implement design for manufacturability and manufacturing information feedback to design.

\section{Research context}

Several studies have examined formal methods to improve PCA's quality by integrating product and process design knowledge through feedback of manufacturing experience in various ways to generate prediction models for yield, cost, reliability and early detection and assessment of assembly problems integrated in software tools of varying degrees of functionality and scope. Methods studied include Rule-Based Reasoning [6, 7], Data mining and statistics [6, 8, 9], CaseBased Reasoning [10-14] and Neural Networks [15, 16]. These methods deal with the formal representation and deployment of various types of knowledge within a company, including design rules, human expertise and 'rules-of-thumb', in-line production and inspection data, experiential knowledge and unknown patterns in data, respectively.

Since the early 1990s several researchers have proposed rule-based advisory tools for various design domains (e.g. manufacturability, test) [7, 17-21]. Srihari's research group have actively researched the development of advisory systems for surface mount technology (SMT) assembly since the early 1990s [7, 22-24]. These systems are mainly limited in scope to solderability, reflow and cleanability issues. Recent focus has been on the integration of cost [25] and reliability [26] design rules in these systems. In addition, similar to Padhy et al [27], rules were built on an object oriented paradigm, allowing for a hierarchical representation of the knowledge that helps to speed up the development of the software [7]. 
Lawlor-Wright and Gallagher [17, 18] proposed the Design for In-circuit Test Advisory (DICTA) system. The tool analyses, at the PCB schematic capture stage, layouts to identify potential in-circuit test (ICT) problems. Bonfield et al. [20] proposed an advisory system, the MIDAS prototype. The rule set consists of 161 rules based on information from relevant IPC standard and texts. More recently, Bajaj et al [28] outlined a process architecture for implementation of a DFM Framework (i.e. the SFM DFM Framework or SDF) to enhance the manufacturability of PCAs. They demonstrated the use of a standards-based information model (STEP AP210) to capture engineering designs richer in content.

In-line production and inspection data has been used to induce design rules and develop statistical models for SMT assembly defect prediction and the control problem. Clark et al. [8] proposed the quality modelling system (QMS). The tool looks at the cause of faults (e.g. assembly faults due to the component package and component faults due to the technology for the component) and from this analysis predictive models are generated. Details of these models are not provided nor their practical application. Nevertheless, the authors claimed that the QMS tool predicted yields with only $5 \%$ error. Li et al. [9] developed statistical regression artificial neural network models between design and process parameters and assembly yield. The models predict the assembly yields with a root mean square (RMS) error less than $5 \%$ and can be used to predict the assembly yield for new board designs on the same line. Joo and Barton [6] presented a means to update design rules based on logistic regression to provide a more consistent and comprehensive revision of said rules. They proposed a formal prescription for maintaining rules consisting of developing statistical models of production cost and yield to create or modify PCA design rules. Fidan [21] presented a computer aided process planning (CAPP) system to detect the defects that necessitate rework for fine pitch SMT laser soldering. The system was developed in Visual Basic (VB) 5, further developed in Java and encoded knowledge in extensible markup language (XML) [29]. The context for this software is in educational institutes by students learning the rework and reflow processes. More recently Yang and Tsai [15] studied the application of the knowledge acquisition capability of a neuro-fuzzy approach to develop a defect prediction and control system for SMT assembly (currently limited to solderability defects). Using commercial fuzzy software, fuzzy rules were obtained that encoded process knowledge. The implementation of the proposed system in a high-volume assembly line reduced defect related downtime by $47 \%$ through better defect prediction and control.

Case-based reasoning (CBR) has been used to represent problem solving experiences as it uses a well known model of human reasoning where human experts solve new problems by adapting solutions that were used to solve prior experiences or cases [30] (see Figure 1). A case in CBR systems has been defined as "a contextualised piece of knowledge representing a previous experience or problem" [30]. A few researchers have studied CBR in order to support problem solving tasks in the manufacturing of electronics [12-14, 31].

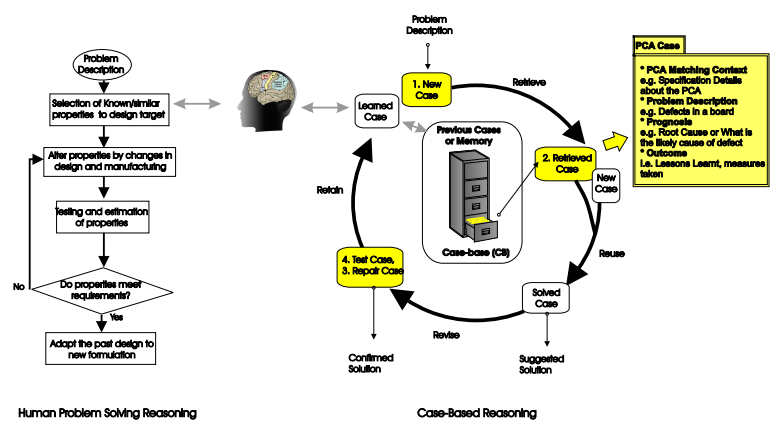

Figure 1. The Case-based Reasoning Cycle.

Tsai et al. [12] studied CBR based on the hypothesis that PCB products with similar design specifications are likely to generate similar defects because similar manufacturing processes and conditions are applied. A simple case description consisted of the following attributes: board thickness, inner layer line width, tin thickness, aspect ratio. The solution part of a case is described by the defects generated and recorded with the solution elements and the cost associated in repairing the defect. In practice a defect item with high cost (e.g. increase in production cost to re-arrange machines) is of interest to PCB manufacturers. The defects attributes they used include inner layer short, pad broken and scratch. The authors limited their findings to the retrieval of similar cases from the case base. The system does not provide any information about what actions to take when a critical defect is considered likely to happen.

Tsai and Chiu [31] have recently extended their research into developing a CBR system to infer the principal process parameters and their value range that affect the quality of a new PCB product. In the proposed system, each PCB product is considered as a case comprised of the PCB product design specifications as the problem description part of a case, and the process and quality parameters involved in all production activities as the solution part. Common process parameters include etching wire-speed, drilling pulsing width, de-smear wire-speed, pulse electric current density and coating weight. Quality parameters include dielectric constant, dielectric loss, glass transition and temperature. In the case retrieval stage of the CBR system, past PCB products that have similar design specifications to the new PCB product are retrieved. When validated with real data, the proposed CBR system helped production managers to reduce the manufacturing lead-time and increase production, though actual figures were not given.

Balakrishnan et al. [32] proposed a prototype circuit diagnostic support system (CDSS) that stores diagnostic cases at a high-volume consumer electronics assembly plant. The population of the case base with diagnostic experiences was attained within a short period of time (5 weeks) covering $90 \%$ of the defects. The system is targeted at improving the unnecessary tests by providing the outcomes of previous tests, permitting users to select a test sequence based on the likelihood of various defects.

We have [14] proposed a CBR system for PCAs in order to capture experiential knowledge when solving problems in a PCA manufacturing line (i.e. root cause investigation and lesson learnt). PCA cases have been represented as a set of 
quantitative and qualitative attributes corresponding to: (i) PCA design and specification features (e.g. materials used, processing methods, reliability), (ii) a defect or problem, (iii) its prognosis or likely cause of the defect and (iv) the root cause of the defect.

A review of the literature has shown that there are a vast number of tools but few products available that offer an integrated solution. Additionally, research by others has neglected the importance of studying the requirements of building a software tool i.e. there was little study of the processes (business, management, design and manufacturing) within an organisation that may impact defect opportunity and its control. A holistic view of an organisation may provide insight into what aspects may be changed and how they may be changed. Furthermore, the overall effect of specific changes may be enabled through the entire life cycle of the manufacturing system through simulation. Enterprise Modelling can be used to describe the activity of modelling any aspect of an organisation.

The remainder of this paper explains the methods used to develop the CLOVES tool and how understanding the requirements through enterprise modelling, provided insight into what aspects may be changed and how they may be changed. The application of traditional artificial intelligence methods, explained above, that also support the knowledgebased tool and are also described. Details of how conventional enterprise modelling techniques were employed within the domain are explained in section 3.1. In section 3.2, the development of a rule-base and case-base that contains information about PCA design for manufacturing best practice and root cause analysis of each of the failed cases respectively are presented. An example of the predictions, which consist of defect opportunities and yield [33] (cost [34] and reliability implications [35] are out of the scope of this paper) is briefly presented. A description of the CLOVES tool illustrating how the software toolkit can be used is presented in section 3.3. Finally, conclusions are drawn on the use of enterprise modelling [36] and case-based reasoning [14] for the evaluation and prediction of the propensity of new designs to exhibit manufacturing defects and the development of the necessary control measures.

\section{Complex Low Volume Electronics Simulation (CLOVES)}

The development of an intelligent knowledge-based system for the prediction of defects and simulation of production capability and product reliability in electronic Printed Circuit Assemblies (PCA) is a collaborative project between a consortium of avionics manufacturers, Warwick University and Loughborough University, with support from the Department of Trade and Industry (DTI) UK. This novel system was aimed at: (i) improving the operational efficiency of plants assembling electronic printed circuit boards by increasing yield and reliability, (ii) improving the competitiveness of the supplier of PCAs, and (iii) increasing the responsiveness of the producers of PCAs to the demands and needs of customers (see Figure 2). A reliability study is out the scope of this paper and will be part of forthcoming publications.

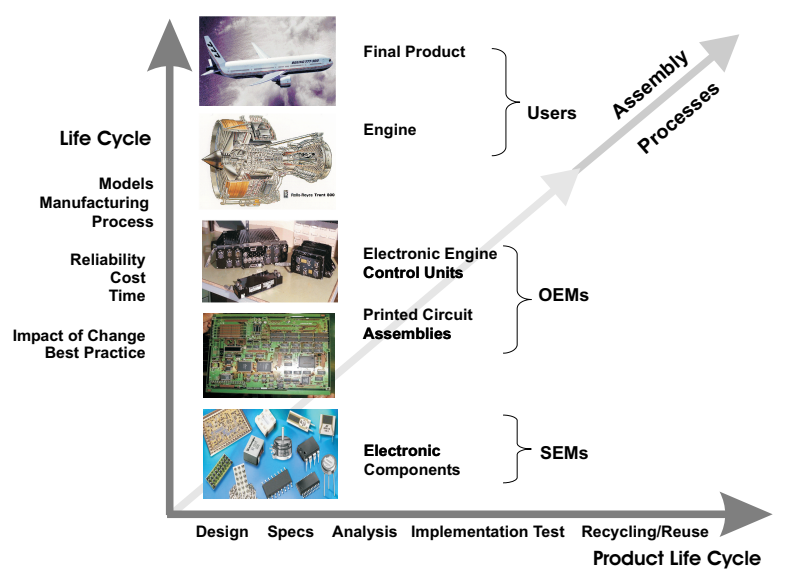

Figure 2. Application context of the CLOVES

Three main objectives have been identified as yield prediction, reliability prediction and defect simulation leading to product optimisation. This paper is focused on describing how enterprise modelling can support eliciting the requirements for the tool and can leverage traditional AI methods (e.g. RBS, CBR, data mining) to obtain adequate parameters that can be used to predict: (i) first time rates yield, (ii) defect opportunities of PCA designs and (iii) the impact measured as reliability and cost on the manufacturing and business strategies. In its full application, the CLOVES system is expected to complement the existing strategies of quality control by leveraging knowledge from data, shop floor, human resources and enterprise models (see Figure 3). It will be utilised to generate calculations and predictions from the engineering "rules" and heuristic knowledge concentrating on products that have been identified as having quality (specifically component defect) issues.

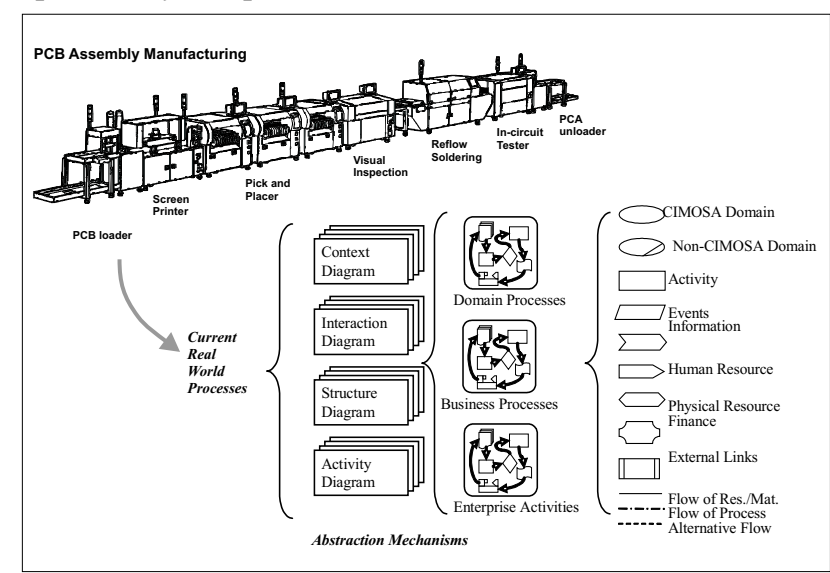

Figure 3. Enterprise modelling can be used to elicit domain requirements. Source: [37]

\subsection{Enterprise Modelling}

Enterprise Modelling consists of eliciting and formally representing the processes that support the internal structure of a business organisation and its relationships with its environment [36]. The MSI Research Institute at Loughborough University has carried out research in Enterprise Modelling and Enterprise Integration over the last decade [38-41]. Areas of application cover large-scale manufacturing and engineering systems including automotive 
and electronics. The modelling approach based upon the CIMOSA (open system architecture for computer integrated manufacturing systems) [42] reference architecture and its application to the electronics manufacturing domain is described in this paper.

Enterprise modelling allows different resource types such as shop-floor personnel, machines, software applications, databases) to be linked in dynamic models by making use of a set of abstraction mechanisms based upon representing real world processes in terms of suite of integrated abstraction "diagrams" (i.e. context, interaction, structure and activity) for the core CIMOSA processes and activities (i.e. domain, business and enterprise) that are composed out of fundamental modelling constructs (e.g. activities, events, information, resources, human resources) (Figure 3).

The models that have been generated cover the different aspects of what an organisation needs to support its activities. A context model (Figure 4) is developed to illustrate the overall research domain under investigation and indicate areas of focus (e.g. Product Design and Product Manufacturing) in which the initial CIMOSA domain models are developed and validated. The supply chain, business management, and customer domain models are not the initial concerns of the industrial partners since the focus is on understanding the capabilities of the production and design activities. The latter is out of the scope of this paper and will not be presented here. Each of the domain models is comprised of business processes: (i) controlled by events that determine the flow of action and (ii) illustrated by constructs representative of the information, time and cost (based upon time and resources used) that are associated with each domain process. A highlevel structure model of the generic manufacturing domain is illustrated in Figure 5. The model illustrates general information about the domain process for that domain. Figure 7 illustrates the Side 1 SMT Process detailing the business process in that domain and the list of activities carried out in each business process. A more detailed model (Figure 7) illustrates the physical and human resources associated with a business process, in this case, the paste printing process.

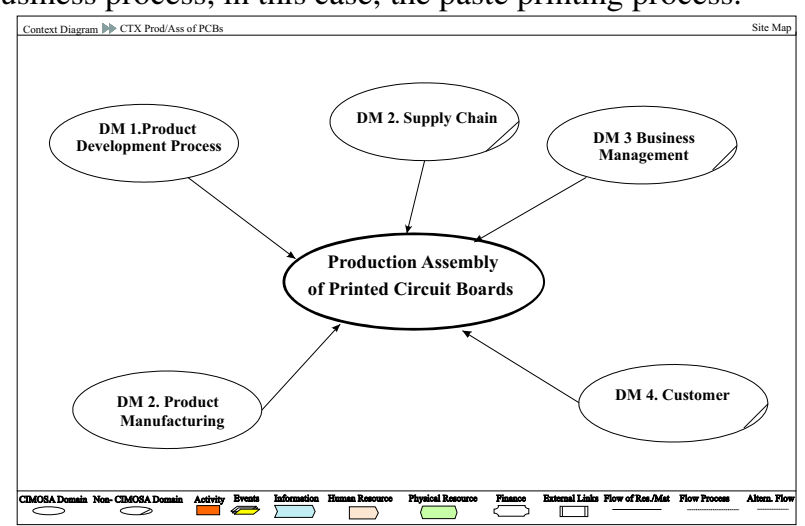

Figure 4. Context diagram

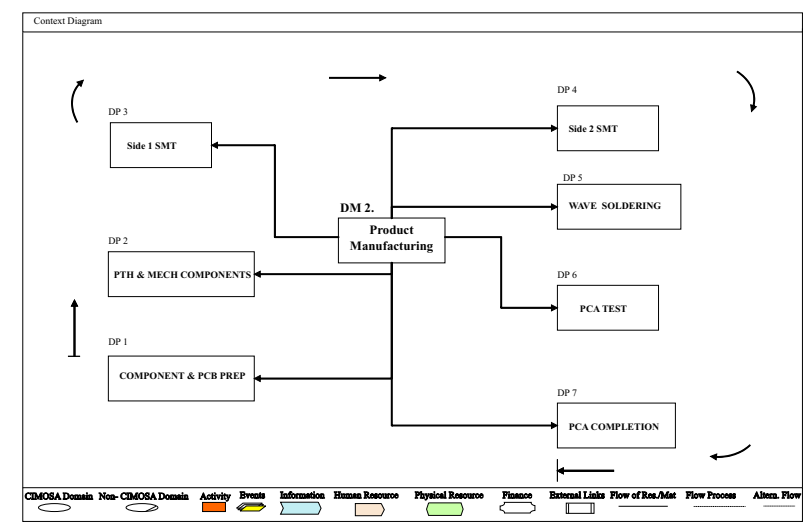

Figure 5. Structure diagram for the Domain DM2. Product Manufacturing

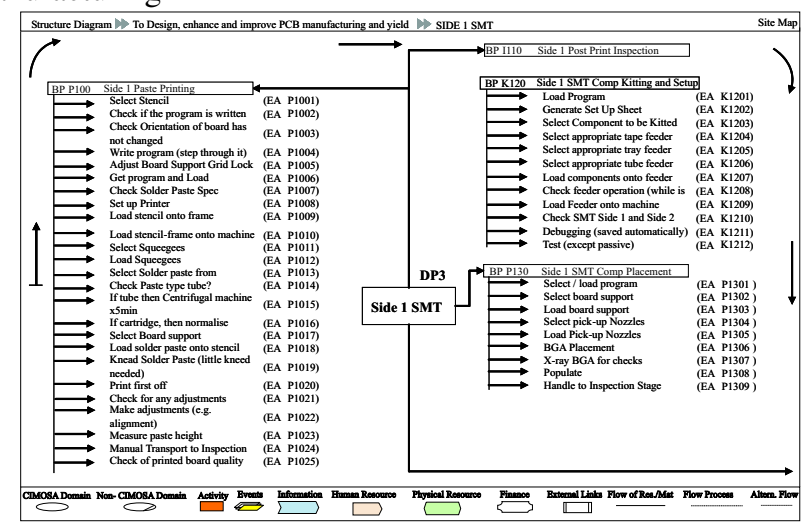

Figure 6. Structure diagram for the Domain Process DP3 Side 1 SMT

As illustrated by Figure 7, the printing process for the first printed board (first-off) starts with the selection of the stencil specified by the 'job pack', or assembly document that states the information necessary to assembly the board. Simultaneously, the operator receives the printing program or loads the program if this is already stored in the machine. After this, a check of the solder paste is carried out, i.e. the paste type is selected and normalised to ambient temperature. The printer is set up by loading the stencil onto a frame and subsequently onto the machine. The squeegees are then selected and loaded and the solder paste is taken from the fridge, manually put onto the stencil and kneaded if necessary. Then a first print is done checked for quality of the printing. Once the printer is adjusted to print as required by the operator, the whole batch of boards is printed and each route card is signed, indicating that the rest of the batch is ready to be printed and the assembly is ready to be transported to the next process stage. 


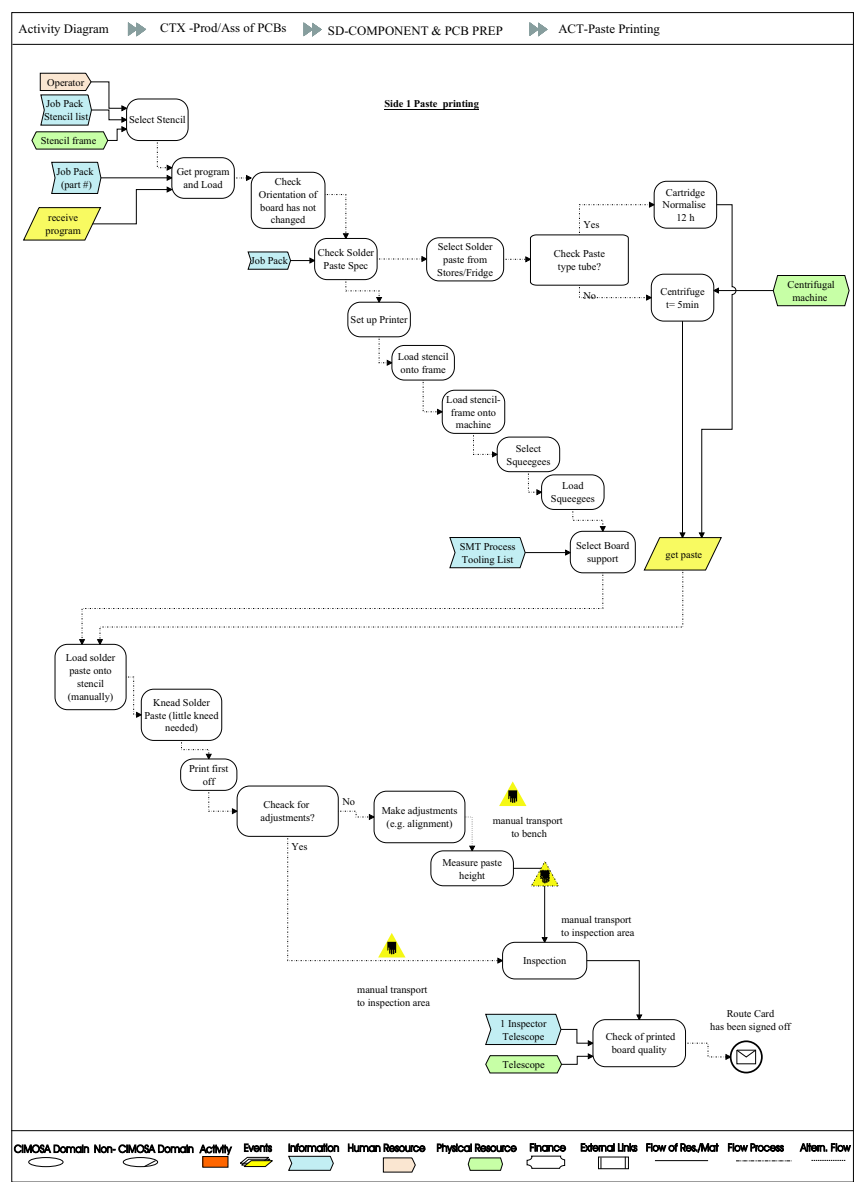

Figure 7. Activity Diagram for the Business Process BP. Paste Printing

The proposed CLOVES integrated software tool serves as a knowledge-base and visualisation tool as well as providing support for knowledge intensive tasks, such as prediction and evaluation, problem solving and simulation (e.g. what-if) and optimisation as shown in Figure 8.

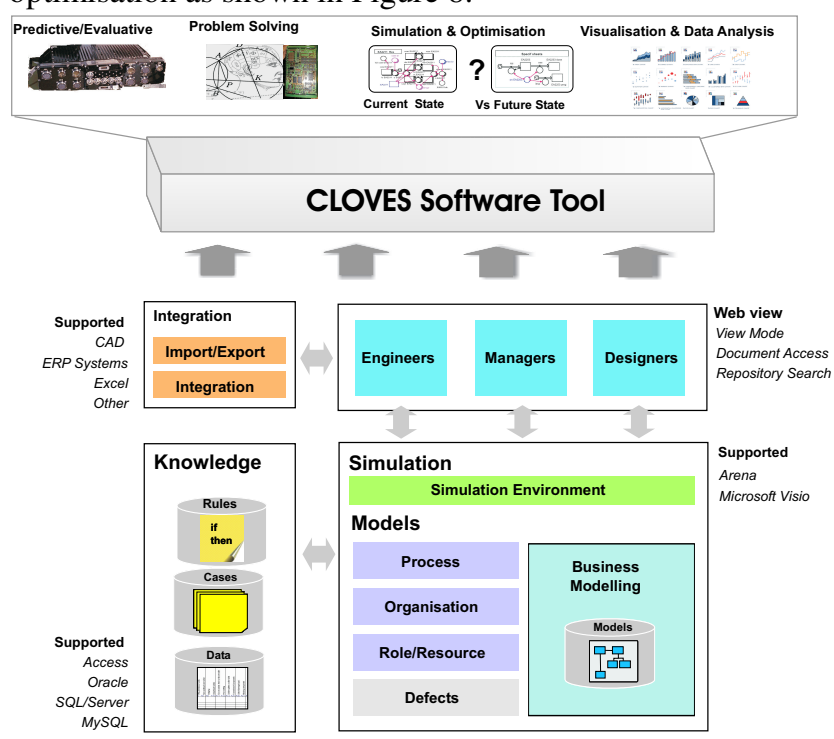

Figure 8. Functional modules of the CLOVES

The CLOVES tool has the capability to (i) create standard graphs (e.g. of real time data and simulation outputs) as desired and (ii) to evaluate the effect of changes in the manufacturing processes on attributes such as time of PCA manufacture, cost, yield, and reliability as desired.

Yield calculations are based on the IPC Standard 9261 "In-process DPMO and Estimated yield for PWAs" [33]. This standard defines the following terms as:

1. DPMO: defined as the total no. of defects divided by the no. of opportunities for a defect multiplied by $1,000,000$

2. Defects per Unit: average no. of defects per assembly

3. Process Step Estimated yield: expected \% of assemblies with no defects for a particular process step or combined steps, based on historical defect rates.

It assumes that (i) all defects identified in the following table are $100 \%$ inspected and (ii) there is a $100 \%$ efficiency.

The calculation of the in-process metric is

$\mathrm{DPMO}_{\mathrm{x}}=\left[\mathrm{d}_{\mathrm{x}} / \mathrm{o}_{\mathrm{x}}\right] \times 10^{6}$

Where the subscript $\mathrm{x}$ refers to a defect category, as follows:

$\mathrm{p}=$ placement defect or opportunity

$\mathrm{t}=$ termination defect or opportunity

$\mathrm{c}=$ component defect or opportunity

$\mathrm{a}=$ assembly defect or opportunity

Predicted yield with DPMO corresponds to

Yield $=$ exp- $[$ (number of defects $)] \times 100 \%$

In addition, CBR circumvents the lack of understanding and quantitative models for predicting defects at both the component and system level through the representation of expert's PCA specifications, defect and historical reliability data into a CBR framework for problem solving. Given a user query, essentially a problem description, similar experiences are retrieved by the CBR system with the ultimate objective of predicting which designs, if any, will allow the resulting product to meet the desired performance criteria. Implementation of the CBR system in an industrial setting will allow: (i) the study of how time and hence the cost of the PCA product development process can be reduced and (ii) most importantly, relevant simulation studies of the production line to optimise yield and reliability.

Using CIMOSA-based models integrated with assembly defect data, simulation of process capabilities and prediction of processing operations on the board quality and cost are being studied via integration of the models with a commercial discrete event simulation engine (i.e. Arena[43]).

In addition to developing an end-user defined custom interface for the simulation module, the use of CIMOSA models has allowed the identification of different users of the tool and their different requirements. Differences are in the scope, user guidance, and output of information. Additionally for the development of simulation scenarios, the modelling activity has been focused on providing and enhancing an environment and on the design and implementation of requirements, whilst the various end-users are focused on the use of the models for decision support and to provide feedback on the particular model supporting their respective area of responsibility.

\section{Conclusions}


This paper introduced the CLOVES tool, which is being developed to support the prediction of quality metrics (e.g. yield, cost, reliability) and early detection of assembly problems and their control. The proposed tool is a support system aimed at electronic designers and manufacturing engineers. The tool uses enterprise modelling in order to obtain a holistic view of the manufacturing process. Enterprise modelling enables the capture and description of the relevant aspects that a user requires, at different abstraction levels, in this case, process activities, organisational structure, information, and resources. The enterprise models can further enable the identification and assessment of solution options and alternative process flows and designs. It enables the representation of a board's manufacturing stages and allows the comparison of different assembly scenarios, suggesting how they can be improved. Enterprise modelling leverages the traditional methods to develop knowledge-based systems (e.g. RBS, data-mining, case-based reasoning) for decision support and problem solving.

Experience with the CLOVES tool has shown that the practical application of the tool in industry requires the integration of data and information from all the knowledge bases across the company. The authors are also working on the application of current generic data transfer standards (e.g. $[33,44,45])$ to enable information integration that facilitate the application of the tool in real time. Analyses achieved with the CLOVES tool, i.e. estimates (i.e. numerical indicators) of the quality and reliability of a PCA being manufactured, are being validated with industrial practitioners. It is notable that the tool not only automates the mathematical parts of the analysis of quality (and other metrics under study not presented here e.g. reliability and cost), but also provides the users with the closest previous designs and the actions taken in solving a problem related to these designs that support the new requirements by means of a CBR system.

\section{Acknowledgments}

The authors wish to express their gratitude to the industrial collaborators. This work was supported financially by the Department of Trade and Industry (DTI) UK.

\section{References}

1. Reed, F.M. and K. Walsh, Enhancing Technological Capability Through Supplier Development: A Study of the U.K. Aerospace Industry. IEEE Transactions on Engineering Management, 2002, 49(3): pp. 231-242.

2. Goosey, M., Implementation of the RoHS directive and compliance implications for the PCB sector. Circuit World, 2007, 33(1): pp. 47-50.

3. Alford, Articles - The Problem with Aviation COTS. IEEE aerospace and electronic systems magazine., 2001, 16(2): pp. 33.

4. Singh, P., P. Sandborn, D. Lorenson, et al., Determining Optimum Redesign Plans for Avionics Based on Electronic Part Obsolescence Forecasts. Society of Automotive Engineers, 2002.

5. Trybula, W.J., The evolution of design for manufacturing. IEEE Technical Applications Conference and Workshops. Northcon/95 (Cat. No.95CH35792), 1995: pp. 4,
6. Joo, Y. and R.R. Barton, Integrated product and process design through feedback of manufacturing experience. Computers and Industrial Engineering, 1995, 28;(3).

7. Krishnan, S. and K. Srihari, A Knowledge-Based Object Oriented DFM Advisor for Surface Mount PCB Assembly. International Journal of Advanced Manufacturing Technology, 1995, 10(5).

8. Clark, A.J., A.J. White, P.G. Leaney, and A.J. Wycherley, A Quality Modeling System for Predicting the Yield of Assembly and Test Processes in the Printed Circuit Assembly Industry. Journal of Electronics Manufacturing, 1995, 5(2): pp. 75-87.

9. Li, Y., R.L. Mahajan, and J. Tong, Design factors and their effect on PCB assembly yield - statistical and neural network predictive models. IEEE/CHMT European International Electronic Manufacturing Technology Symposium, 1993: pp. 353-361.

10. Cunningham, P., B. Smith, and A. Bonzano, An Incremental Retrieval Mechanism for Case-Based Electronic Fault Diagnosis. Journal of Knowledge Based Systems, 2002.

11. Lee, C.K.M., H.C.W. Lau, and K.M. Yu, An objectbased knowledge integration system for product development: A case study. Journal of Manufacturing Technology Management, 2005, 16(2): pp. 156-177.

12. Tsai, C.-Y., C.-C. Chiu, and J.-S. Chen, A Case-based reasoning system for PCB defect prediction. Expert Systems with Applications, 2005, 28: pp. 813-822.

13. Vollrath, I. Reuse of Complex Electronic Designs. Requirements Analysis for a CBR Application. in Proceedings of the Fourth European Workshop on CaseBased Reasoning. 1998. Berlin: Springer Verlag. pp 136- 147.

14. Segura Velandia, D.M., A.A. West, P.P. Conway, and D.C. Whalley. A Case-Based Reasoning Approach for Low Volume, High Added Value Electronics. in 8th Electronics Packaging Technology Conference, EPTC 2006. 6- 8 December 2006 2006. Pan Pacific Hotel, Singapore.

15. Yang, T. and T. Tsai, Modeling and implementation of a neurofuzzy system for surface mount assembly defect prediction and control. IIE Transactions, 2002, 34(7): pp. 637-646.

16. West, A., C. Hinde, C. Messom, et al., Design issues associated with neural network systems applied within the electronics manufacturing domain. Journal of Electronics Manufacturing, 2000, 10(1): pp. 19-48.

17. Lawlor-Wright, T. and C. Gallagher, Development of a printed circuit board design for in-circuit test advisory system. Computers in Industry, 1997, 33(2-3): pp. 253-3.

18. Lawlor-Wright, T., Design for testability of printed circuit board assemblies. Colloquium Digest - IEE, 1997(16).

19. Gao, J. and G. Bennett, The development of a rules-based CAPP system for electronic circuit assembly. International Journal of Computer Applications in Technology, 1998, 11(6): pp. 436-441.

20. Bonfield, T. and M. Barber, A Multiple-Perspective Design Advisory System for Use in the Layout Design of 
Printed Circuit Board Assemblies. IEEE transactions on electronics packaging manufacturing : a publication of the IEEE Components, Packaging, and Manufacturing Technology Society, 2003, 26(2): pp. 115.

21. Fidan, I., CAPP for electronics manufacturing case study: Fine pitch SMT laser soldering. Journal of Electronic Packaging, 2004, 126(1): pp. 173-176.

22. Wu, C.-H. and K. Srihari, Automated knowledge acquisition for the surface-mount PWB assembly domain. Journal of Intelligent Manufacturing, 1996, 7(5): pp. 393-398.

23. Ramakrishnan, S., K. Srihari, and G.R. Westby, Manufacturing-Electronics. A decision support system for the alternative assembly and reflow technology process. Computers \& Industrial Engineering, 1998, 35(1-2): pp. 61-2.

24. Wu, C.-H., S.-C. Kao, and K. Srihari, GDKAT: a goaldriven knowledge acquisition tool for knowledge base development. Expert Systems, 2000, 17(2): pp. 90-105.

25. Nagarajan, K., D.L. Santos, and K. Srihari. A cost estimation tool for BGA and DCA technology. in Proceedings of the 1996 International Electronics Packaging Conference. September 1996. Austin, TX. pp 67.

26. Gnanasambandam, N., A. Primavera, and K. Srihari, The reliability prediction of electronic packages: an expert systems approach. International Journal of Advanced Manufacaturing Technology, 2005, 27(3-4): pp. 381-391.

27. Padhy, S.K. and S.N. Dwivedi, An Object-Oriented Knowledge-Based System for Manufacturability of Printed Wiring Boards. Computers in Industry, 1992, 18(1): pp. 77-89.

28. Bajaj, M., R. Peak, M. Wilson, et al. Towards nextgeneration design-for-manufacturability (DFM) frameworks for electronics product realization. in 28th International Electronics Manufacturing Technology Symposium. 2003. Piscataway, NJ, USA: IEEE. pp 67.

29. Fidan, I., E. Roush, S. Tumkor, and R. Kraft, Internetbased electronics manufacturing troubleshooting tool for surface mount PCB assembly. International Journal of Advanced Manufacturing Technology, 2006, 27(5-6): pp. 561-567.

30. Kolodner, J.L., Case-based reasoning. 1993, San Mateo, CA: Morgan Kaufmann Publishers

31. Tsai, C. and C. Chiu, A case-based reasoning system for PCB principal process parameter identification. Expert Systems with Applications, 2007, 32(4): pp. 1183-1193.

32. Balakrishnan, A. and T. Semmelbauer, Circuit diagnosis support system for electronics assembly operations. Decision Support Systems, 1999, 25(4): pp. 251-269.

33. IPC-9261, In-Process DPMO and Estimated Yield for PWAs. IPC, 2002.

34. Niazi, A., J. Dai, S. Balabani, and L. Seneviratne, Product cost estimation: Technique classification and methodology review. Journal of Manufacturing Science and Engineering-Transactions of the ASME, 2006, 128(2): pp. 563-575.

35. Marshall, J., L. Walls, and J. Jones, Reliability enhancement methodology and modelling - the REMM project. The Aeronautical journal., 2002, 106: pp. 195202.

36. Fraser, J. Managing Change through Enterprise Models. in Applications and Innovations in Expert Systems. Proceedings of Expert Systems 94, the Fourteenth Annual Technical Conference of the British Computer Society Specialist Group on Expert Systems. 31 December 1994. Cambridge, UK.

37. Monfared, R.P., Practical Application of Enterprise Modelling. 2003: Wolfson School of Mechanical and Manufacturing Engineering, Loughborough University.

38. Monfared, R.P., B.A. Bowen, A. Hodgson, and A.A. West, Implementing a Model-Based Generic User Interface for Computer Integrated Manufacturing Systems. Proceedings of the Institution of Mechanical Engineers Part B: Journal of Engineering Manufacture, 1998, 212: pp. 501-516.

39. Monfared, R.P. A component-based approach to design and construction of change capable manufacturing cell control. PhD Thesis, Loughborough University, 2000.

40. Edwards, P.R., Manufacturing Technology in the Electronics Industry. An Introduction. 1991, London: Chapman and Hall

41. Weston, R.H., A.A. West, R. Harrison, et al. Use of CIMOSA and Systems Thinking to document and inform the design and development of car engine production systems. in Proceedings of the 10th ISPE International Conference on Concurrent Engineering Research and Application, Enhanced Interoperable Systems, . 28-31 July 2003. Madeira. pp 851.

42. Vernadat, F., Enterprise Modeling and Integration. First ed. 1996: Chapman and Hall

43. Arena. 2007 11.00.00-CPR7 Rockwell Automation Technologies http://www.arenasimulation.com/

44. Delamer, I.M. and J.L. Martinez Lastra, Quality of service for CAMX middleware. International Journal of Computer Integrated Manufacturing, 2006, 19(8): pp. 784-804.

45. Spera, J., Making Sense of CAMX Initiatives - A new solution improving information availability is allowing manufacturers to distinguish themselves as uniquely efficient in the maturing market. Electronic packaging and production, 2002, 42(11): pp. 20. 